\title{
Histórias do olhar: o visível, o \\ legível e as interpretações sobre a \\ fotografia V-J Day in Times Square
}

\author{
Diana Silveira de Almeida ${ }^{1}$ \\ DOI 10.20396/eha.vil4.3323
}

Já dizia Didi-Huberman: as imagens são dialéticas. Elas permitem a troca de experiência e a compreensão de significados a cada vez que as vemos. Nós ol hamos com a nossa cultura, com as nossas vivências e com a nossa personalidade, mas, também, com as interpretações que já estão prontas, as que são trazidas até nós pela história da arte, pelo catálogo do museu, pelo relato dos professores, pela escrita do autor/artista, pelos sites da internet, etc.

Tomando como exemplo os percursos de uma imagem e os discursos que são produzidos a partir da visualidade, este trabalho pretende abordar teorias da história da arte, seu campo contextual e as múltiplas maneiras de olhar para a fotografia histórica norte-americana V-j Day in Times Square (Figura 1) ${ }^{2}$.

Para a análise da fotografia e de seus discursos serão trabalhados os saberes visíveis, legíveis e invisíveis de uma imagem dialogados por Didi-Huberman (2013). No entanto, é valendo-se da crença de que a imagem não deve sua eficácia somente a tais saberes, que também serão abordados outras maneiras de olhar para a imagem. Consideram-se alternativas como a "imaginação modeladora" ${ }^{3}$, que direciona o autor a criar sua própria verdade, colocando no texto suas ideologias e considerações. Além disso, trata-se, também, do anacronismo que, em termos de subjetivação e memória, é a teoria que permite a distância histórica cultural entre aquele que analisa e aquilo que é analisado. Ao tratar sobre a eficácia da imagem, Didi-Huberman ressalta que

(...) as imagens são devem sua eficácia apenas à transmissão de saberes, sua eficácia, ao contrário, atua constantemente nos entrelaçamentos ou mesmo no imbróglio de saberes transmitidos e deslocados, de não-saberes produzidos e transformados. Ela exige, pois, um olhar que não se aproxima apenas para discernir e reconhecer, para nomear a qualquer preço o que percebe - mas que primeiramente se afastaria um pouco e se absteria de clarificar tudo de imediato. Algo como uma atenção flutuante, uma longa suspensão do mo-

\footnotetext{
1 Universidade Federal de Pelotas, mestra em História.

2 O foco deste trabalho é o de pensar sobre os discursos que surgem a partir da repercussão da imagem. Uma análise sobre as referências visuais de sua constituição pretende ser realizada em outro momento.

3 HUTCHEON, 1991.
} 


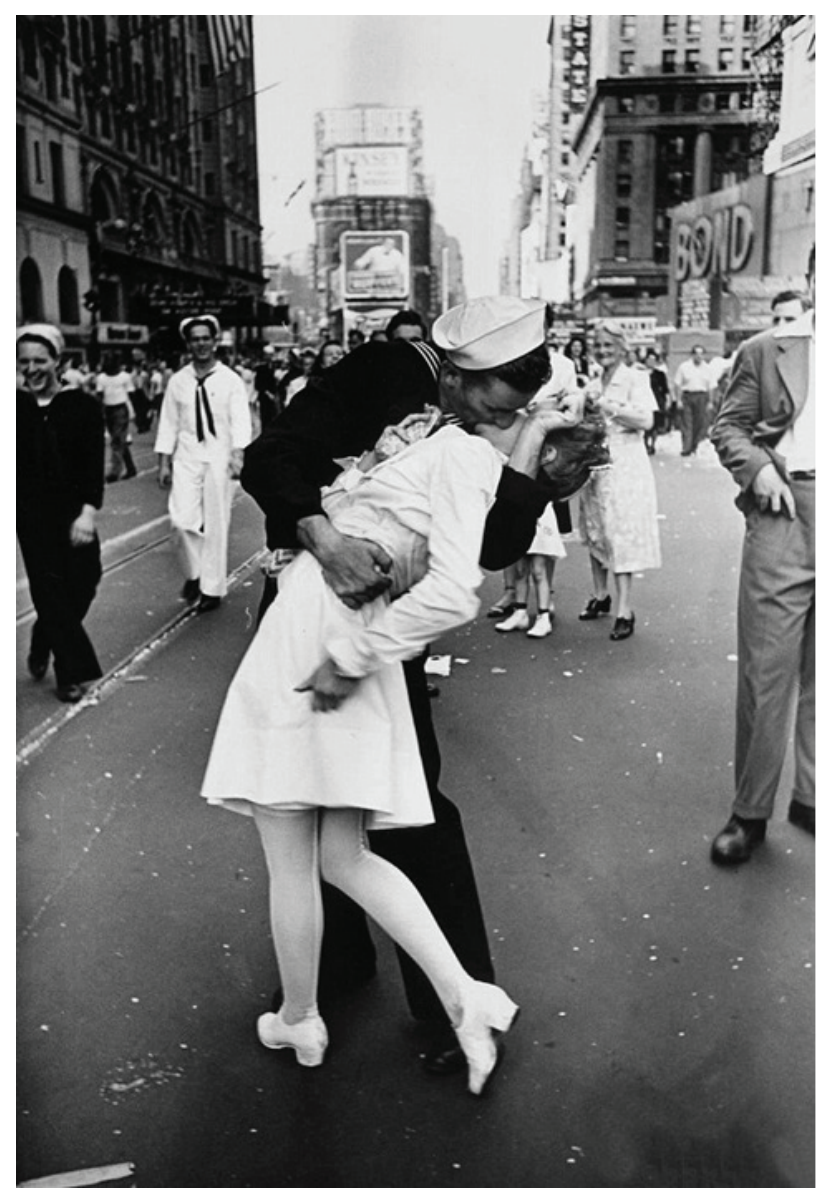

[Figura 1] Alfred Eisensteadt. V-] Day in Times Square. Fotografia, 14/08/1945. 
mento de concluir, em que a interpretação teria tempo de se estirar em várias dimensões, entre o visível apreendido e a prova vivida de um desprendimento ${ }^{4}$.

Portanto, é na proposta de olhar para a fotografia de várias maneiras que serão abordados diferentes aspectos interpretativos. Espera-se que a partir dos entrelaçamentos de saberes seja possível alcançar conhecimento histórico e artístico mediante as possibilidades permitidas pela imagem.

É muito comum que as pessoas tratem ou falem sobre visível, mas o que, de fato, é visível em uma imagem? Segundo Didi-Huberman, são os "elementos discerníveis enquanto signos" 5 . Em outras palavras, é aquilo que se pode ver; é a primeira análise visual, que fora anteriormente chamada por Panofsky (2011) de "pré-iconográfica". Essa maneira de olhar é aquela que não agrega conhecimentos além do que se pode ver.

Por exemplo, ao olhar para V-J Day in Times Square pode-se dizer que o visível se caracteriza pelos seus elementos constituintes, isto é, a imagem possui personagens e cenário reconhecíveis em uma composição definida pela simetria e perspectiva permitidas pela arquitetura urbana. Em primeiro plano, reconhecemos um homem e uma mulher em meio a um beijo. Eles estão em um lugar público e sua ação parece passar despercebida por outras pessoas que estão ao redor e muitas dessas pessoas estão vestidas da mesma maneira que eles.

Quanto ao legível, é o que traduz ou evoca "unidades mais complexas, temas ou conceitos, histórias ou alegorias" ${ }^{6}$. É a leitura iconográfica que permite o reconhecimento e a significação do visível. Pode-se dizer, ainda, que na fotografia, as pessoas se encontram na Times Square, em Nova Iorque, nos Estados Unidos da América. O homem que aparece em primeiro plano está vestido com o uniforme da marinha dos EUA da década de 40, assim como outros que aparecem em segundo plano. A mulher, por sua vez, está vestida com o uniforme das enfermeiras que atuaram na Segunda Guerra Mundial.

A partir destas primeiras leituras, tornam-se viáveis outras maneiras de olhar para esta mesma imagem. Por ser uma fotografia famosa, muito foi produzido entre matérias jornalísticas, discursos, vídeos, e, inclusive, outras imagens que tomam V-J Day in Times Square como referência primária. A história e os percursos desta famosa fotografia americana serviram como fontes para que a presente pesquisa pudesse ser realizada.

\footnotetext{
4 DIDI-HUBERMAN, 2013, p. 23-24.

5 DIDI-HUBERMAN, 2013, p. 20.

6 DIDI-HUBERMAN, 2013, p. 20.
} 


\section{Percurso da imagem V-J Day in Times Square}

Em 14 de agosto de 1945, toda a nação dos Estados Unidos da América recebeu a notícia de que o Japão havia se rendido e a Segunda Guerra Mundial havia terminado. O fotógrafo Alfred Eisenstaedt, que na época trabalhava para a revista Life, estava em serviço registrando as comemorações na Times Square, quando capturou quatro imagens de um marinheiro e uma enfermeira em meio a um beijo. Uma dessas fotografias foi publicada na Life, no dia 27 de agosto e, em pouco tempo, tornou-se a imagem mais reproduzida da revista. A fotografia passou a ser considerada a representação da felicidade do fim da guerra, expressa pelo beijo de um casal apaixonado. Essa postulação de imagem ícone é encontrada em diversas fontes bibliográficas (livros de história, história da arte e história da fotografia). Um desses registros pode ser exemplificado na seguinte passagem:

sua foto [do fotógrafo Alfred Eisenstaed] de um marinheiro beijando uma enfermeira em comemoração da rendição japonesa capta a euforia dos Aliados quando a guerra acabou em 14 de agosto de 1945. A foto foi impressa na edição "da Vitória" da Life. O marinheiro e a enfermeira, simbolizando os soldados e o corpo médico, de apoio, estão enfim livres do conflito e, por um dia eufórico, das convenções sociais ${ }^{7}$.

Conforme a fama da imagem crescia, a identidade dos personagens da fotografia passou a ser questionada. As pessoas queriam saber, de modo análogo ao desenrolar de um romance, quem era o casal apaixonado da foto e onde eles estavam agora. Não demorou muito para que, vários casais que se enquadravam nos dados da fotografia (rapazes que foram marinheiros e moças que foram enfermeiras no ano de 1945) enviassem cartas para a revista Life e para Eisenstaed, dizendo serem as pessoas da foto. Cada um contava uma história diferente e mais de uma história foi considerada como a "verdadeira".

Em agosto de 1980, a revista Life publicou uma reportagem dizendo que o mistério havia sido solucionado: o fotógrafo recebera uma carta convincente de Edith Shain que dizia ser a enfermeira da foto. Em uma entrevista concedida ao New York Nightly News no ano de $2009^{8}$, Edith Shain alegou que estava em serviço quando ouviu no rádio a notícia de que a guerra havia acabado. Ela e um amigo foram para a Times Square onde todos estavam celebrando. A enfermeira diz que não sabe de onde o marinheiro veio. Ele a segurou por um longo tempo beijou-a e foi embora. A história da moça convenceu o fotógrafo e ela, por sua vez, ficou instantaneamente famosa, passando a apare-

\footnotetext{
7 HACKINC \& CAMPANY [org.], 2012, p. 315.

8 Entrevista disponível em: https://www.youtube.com/watch?v=CjoO1fNxVn4. Acesso em: 06/02/2016.
} 
cer nos jornais, eventos sociais e em entrevistas - vestida nos trajes de enfermeira do ano de 1945.

No entanto, dois anos após a morte de Edith Shain, ocorrida em 2010, outra surpresa foi revelada à nação: a suposta enfermeira não era a moça da foto. Na verdade, Greta Zimmer Friedman, uma austríaca que havia perdido os pais na Primeira Guerra Mundial e fora tentar a sorte nos EUA. Isso, segundo as informações do livro divulgado em 2012 pelo US Naval Institute, chamado The Kissing Sailor: The Mistery Behind the Photo that Ended the World War II ${ }^{9}$. O livro relata, ainda, que o marinheiro da foto era George Mendonsa, que é a pessoa que narra essa versão. Ele estava em um encontro com Rita Petrie (que se tornou sua esposa), quando o fim da guerra foi anunciado. Mendonsa tomou alguns "drinks" em comemoração ao evento e mais tarde, quando eles estavam na rua, ao ver uma mulher com o uniforme de enfermeira, ele deixa Rita e sai correndo para beijar a outra mulher.

Em uma entrevista concedida à CBS News em $2012^{10}$, George Mendonsa diz que o beijo não foi muito demorado, diferente do que a enfermeira Edith Shain havia afirmado anteriormente. Nesta mesma entrevista, o repórter pergunta para Greta Zimmer se ela havia visto a publicação da fotografia na revista Life e ela responde com um taxativo "com certeza". E, quando perguntam para ela se ela se reconheceu, a resposta é: "mas é claro, você não esquece um rapaz desses agarrando você". Mendonsa diz que uma das provas de que ele é o marinheiro da fotografia, é a imagem de Rita que também está retratada. Ela seria a mulher sorridente que aparece mais atrás na altura do braço esquerdo do marinheiro. Rita, por sua vez, alega que não se incomodou com o beijo dado em outra mulher. Segundo eles, após o beijo cada um seguiu seu caminho.

Muitos dos detalhes contados nas narrativas são questionáveis, porém o simples fato de a suposta verdade ter sido desmentida mais de uma vez já coloca em dúvida qualquer história vigente. Em cada uma dessas versões que a imagem e a sua repercussão provocaram, vemos a construção de um discurso que intenta uma melhor aproximação da verdade, para a aprovação do público, que, por sua vez, adota esses discursos se eles forem aceitos previamente pelas mídias das quais usufruem. No entanto, independente da veracidade dos discursos produzidos, pode-se observar na prática a teoria de Didi-Huberman (2013) que considera o imaginário e o sonho como matérias de criação para a "figurabilidade", que é a capacidade humana de inventar corpos impossíveis "1.

9 O US Naval Institute não só divulga como também vende os exemplares do livro, disponíveis em: http://www.usni.org/store/books/ aircraft-reference/american-fighters/kissing-sailor. Acesso em: 06/02/2016. A história também foi adotada pelo American Veterans Center, que produziram um vídeo com George Mendonsa contando como foi aquele dia. Este vídeo está disponível em: https://www.youtube.com/ watch?v=AKx5TpdokvY. Acesso em 06/02/2016.

10 Entrevista disponível em: http://www.cbsnews.com/news/sailor-nurse-from-iconic-vj-day-photo-reunited/. Acesso em 06/02/2016.

11 DIDI-HUBERMAN, 2013. 
Porém, não se percebe a invenção de corpos e sim a invenção de realidades: a adequação das palavras e das atitudes para que o discurso se torne real e aceito. É uma "sintomatização do mundo visível" ${ }^{12}$, outra maneira de olhar para o imaginário criado pela imagem. Sobre essa relação de interpretação e história, Linda Hutcheon (1991) argumenta sobre a "imaginação modeladora", que relaciona aspectos ficcionais ao discurso. Assim sendo:

a ficção e a história são discursos, e ambas constituem sistemas de significação pelos quais damos sentido ao passado ("aplicações da imaginação modeladora e organizadora"). Em outras palavras, o sentido e a forma não estão nos acontecimentos, mas nos sistemas que transformam esses "acontecimentos" passados em "fatos" históricos presentes. Isso não é um "desonesto refúgio para escapar à verdade", mas um reconhecimento da função de produção de sentido dos construtos humanos ${ }^{13}$.

Segundo a autora, a autoconsciência teórica sobre a história e a ficção como criações humanas, que passa a ser a base para pensar uma reelaboração das formas e dos conteúdos do passado. Assim, entende-se que essas percepções humanas são determinantes para a produção de sentido dos acontecimentos históricos. Mas, não apenas os discursos podem ser vistos dessa maneira, existem outros conceitos e percepções que partem da imagem, como se pode observar na Figura 2.

A Figura 2 é uma imagem salva da internet, especificamente no dia 6 de fevereiro de 2016, somente dois dias depois de sua publicação. A polêmica por trás das informações passadas a partir da imagem (que até então era considerada romântica) e, do tema que a página mostrou (uma discussão sobre consentimento da mulher e atitudes machistas), foi tamanha que dois dias depois da publicação já havia 2 mil comentários, 42.254 curtidas e 8.531 compartilhamentos. Fica em destaque o comentário da Zulmira que, em outras palavras, não havia percebido essa conotação de abuso até ler uma matéria que afirma a presença do ato abusivo na imagem. A conclusão de seu comentário é "A gente só vê o que quer ver".

Com isto em mente, pode-se considerar o anacronismo e a sua importância perante a maneira de olhar para as imagens e para a história. Teoricamente, o anacronismo se caracteriza pelo entendimento de que há uma distância histórica cultural entre aquele que analisa e aquilo que é analisado. Considera que o passado está em constante transformação, na medida em que é construído através da memória, ou melhor, da subjetivação daquele que a constrói. Essa vertente compreenderá que partir das considerações do presente é fundamental, pois "o olhar sobre as práticas

\footnotetext{
12 DIDI-HUBERMAN, 2013, p. 37

13 HUTCHEON, 1991, p. 122.
} 


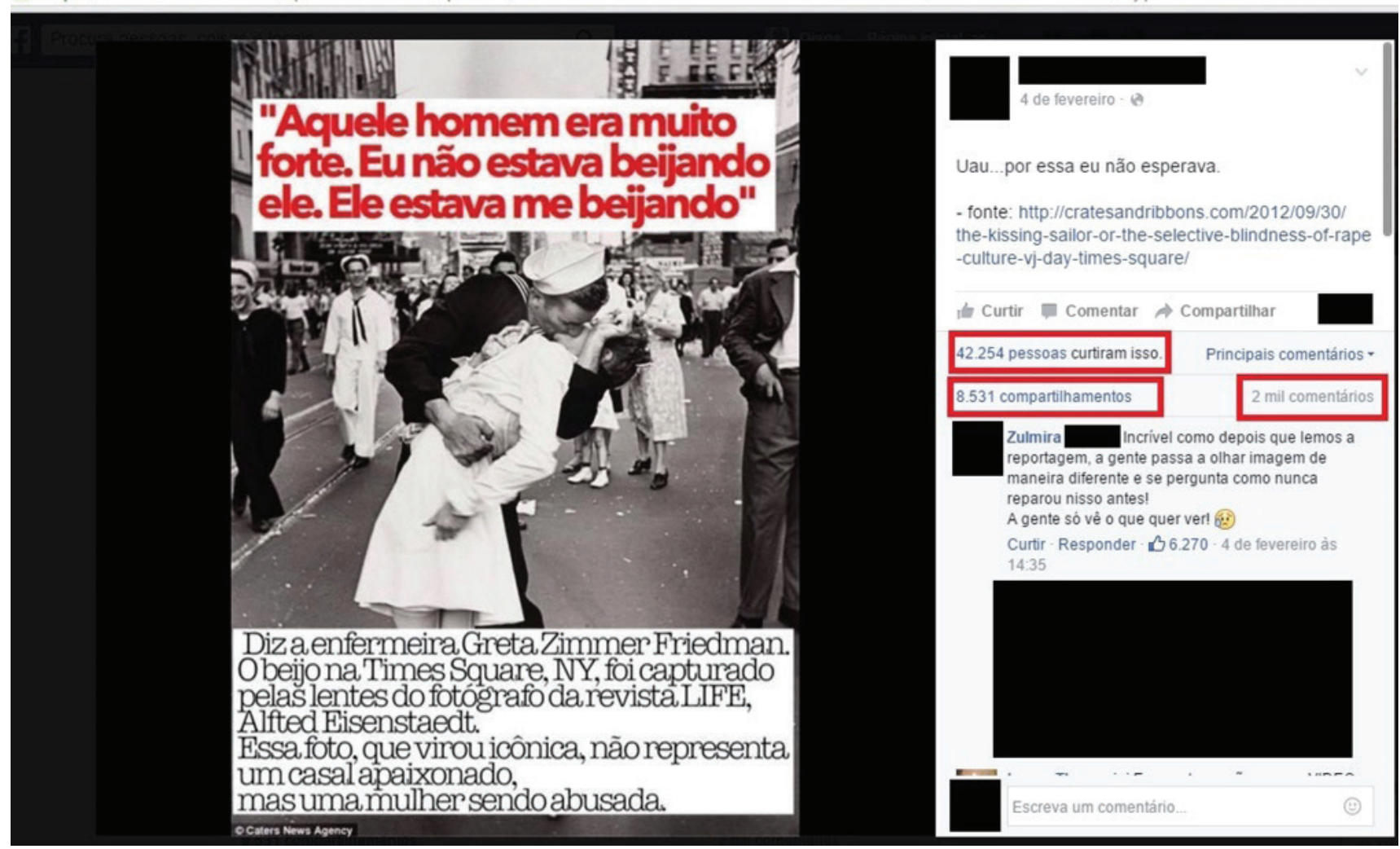

[Figura 2] Diana Silveira de Almeida. Repercussão de um discurso acerca da imagem nas redes sociais.

Print Screen e montagem da autora, 2016.

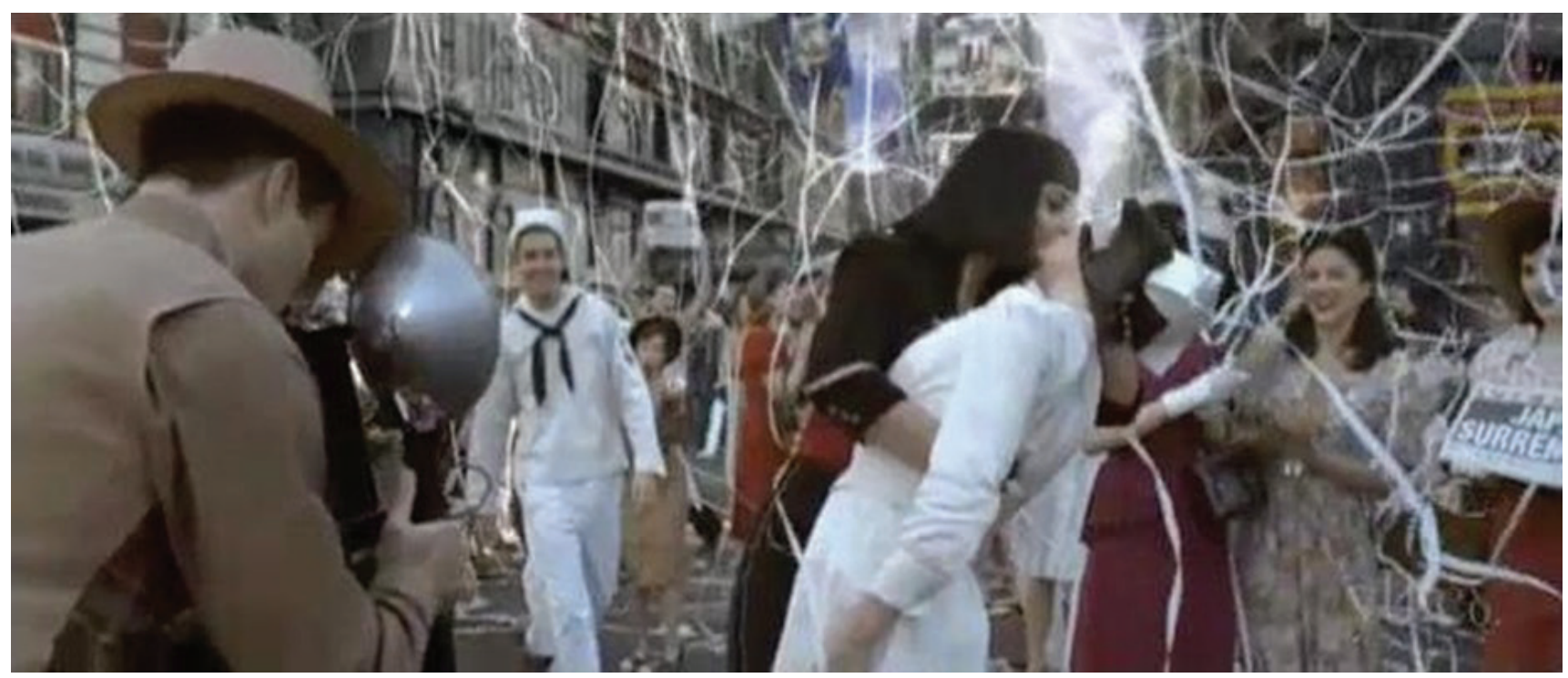

[Figura 3] Zack Snyder. Releitura de V-] Day in Times Square na abertura de Watchmen: o filme (2009).

Print Screen, 2019. 
contemporâneas permite ao historiador comparar e refletir sob outras premissas a respeito do passado" ${ }^{14}$, possibilitando a construção de saberes e não somente a constatação de fatos.

É o caso da interpretação da fotografia V-j Day in Times Square. Apesar da declaração de Creta Zimmer Friedman de que ela havia sido agarrada, ela provavelmente não consideraria que aquele beijo havia sido um abuso. Esta concepção ainda tem sido debatida e discutida nos dias de hoje. Trata-se, portanto, de uma ação anacrônica que modifica a concepção de passado que havia sido propagada. Desta maneira, podemos perceber detalhes do funcionamento da nossa sociedade ao constatar-se que uma forma de abuso fora romantizada, aceita, permitida e, até mesmo, desejada (afinal, por algum motivo, muitas mulheres afirmaram ser a enfermeira da foto).

O anacronismo também possibilita a abertura para a criação de releituras que abordarão o tema da imagem com o olhar contemporâneo, como pode-se observar na Figura 3, por exemplo. Ela retrata exatamente o mesmo cenário e os mesmos acontecimentos apresentados em V-] Day in Times Square. No entanto, dois elementos são modificados: 1) a presença do fotógrafo; e, 2) a modificação do personagem masculino, agora sendo uma das heroínas do filme a beijar a enfermeira.

Essa releitura apresenta a questão do gênero que pode ser percebida tanto no beijo trocado entre as personagens como também na colocação de uma mulher representando um herói de guerra. Aqui, a mulher ocupa a posição de domínio que antes pertencia ao marinheiro, invertendo os valores dos gêneros bem aceitos na década de 40. Essa releitura anacrônica consegue desestabilizar a iconografia pregada pela imagem até então, e desacomoda o olhar patriarcal de mulher com papel submisso imposto pela diferenciação de gêneros ${ }^{15}$.

Pode-se observar, portanto, que o olhar contemporâneo voltado ao passado permite a clarificação do intrínseco, a saber: o que está além do descritível, ou, nas palavras de Didi-Huberman, o que é "invisível" em que "uma metafísica é possível, desde o simples fora de campo inexistente do quadro, até o mais além ideal da obra inteira" ${ }^{16}$. Para o autor, o invisível, ao lado do que é visível e legível, são leituras que permitem a transmissão de saberes existentes em uma imagem. Porém, não é somente nessas maneiras de olhar que reside o conhecimento.

Como dito anteriormente, a eficácia da imagem está nos entrelaçamentos, nos múltiplos saberes e também no não-saber. Está nas diversas maneiras de olhar a imagem, sendo esta a partir de uma leitura contextual, iconográfica, iconológica, imaginada, modelada, anacrônica, e também

\footnotetext{
14 KERN, 2006, p. 74

15 HEARTNEY, 2002.

16 DIDI-HUBERMAN, 2013, p. 23
} 
do olhar livre de intervenções teóricas, desprendido. Está também na "dialeticidade", que consiste em "não apreender a imagem, mas deixar-se antes ser apreendido por ela" ${ }^{17}$. Ao apresentar os percursos da imagem V-J Day in Times Square, este trabalho objetivou mostrar a diversidade de olhares existentes perante a fotografia. Pretendeu, ainda, pensar que existem outras maneiras que não foram abordadas aqui, já que uma vez que a imagem está aberta à "dialeticidade" e ao olhar anacrônico, muito pode ser feito, pensado e criado a partir dela. Conclui-se, portanto, que a eficácia das imagens não está somente na produção do conhecimento acadêmico que ela permite, mas também nos atravessamentos que ela possibilita.

Referências Bibliográficas

DIDI-HUBERMAN, G. Diante da Imagem: questão colocada aos fins de uma história da arte. São Paulo: Editora 34, 2013.

O que vemos, o que nos olha. São Paulo: Ed. 34, 1998.

HACKING, ]. \& CAMPANY, D. (org.). Tudo sobre Fotografia. Rio de Janeiro: Sextante, 2012.

HEARTNEY, E. Pós-Modernismo. São Paulo: Cosac \&Naify, 2002.

HUTCHEON, L. Poética do pós-modemismo: história, teoria, ficção. Rio de Janeiro: Imago Ed., 1991.

KERN, M. L. B. Historiografia da arte: mudanças epistemológicas contemporâneas. $1^{\circ}{ }^{\circ}$ Encontro Nacional de Pesquisadores de Artes Plásticas - ANPAP. Florianópolis, 2007; p. 371-380. Disponível em: http://www.anpap.org.br/ anais/2007/2007/artigos/038.pdf (acesso em 28/10/2019).

MILLER, M. Sailor, nurse from iconic V] Day photo reunited. Disponivel em: http://www.cbsnews.com/news/sailornurse-from-iconic-vj-day-photo-reunited/. Acesso em: 06/02/2016.

PANOFSKY, E. Significado nas artes visuais. São Paulo: Perspectiva, 2011.

PUGLIESE, Vera. A proposta de revisão epistemológica da historiografia da arte na obra de Didi-Huberman. In: I Encontro de História da Arte IFCH UNICAMP, 2005, Campinas. Anais do I Encontro de História da Arte IFCH UNICAMP- Revisão Historiográfica. Brasília: IFCH - Unicamp, 2004. v. 3. p. 208-216.

YOUTUBE. Edith Shain V] Day 2009 Interview. Disponivel em: https://www.youtube.com/watch?v=CjoO1fNxVn4. Acesso em: 06/02/2016.

Profiles in Valor: George Mendonsa, "The Kissing Sailor". Disponivel em: https://www.youtube.com/watch?v=AKx5TpdokvY. Acesso em: 06/02/2016.

17 DIDI-HUBERMAN, 2013, p. 24 